\title{
Partisipasi Forum Anak Banyumas Dalam Mewujudkan Kabupaten Layak Anak di Kabupaten Banyumas Ditinjau dari Perspektif Multi Stakeholder Partnerships
}

\author{
Irma Alviana ${ }^{1}$, Slamet Rosyadi ${ }^{2}$, Simin $^{3}$, Rukna Idanati ${ }^{4}$ \\ 1,2,3,4 Program Studi Administrasi Publik, FISIP Universitas Jenderal Soedirman \\ Jl. Kampus No.12, Brubahan, Grendeng, Kec. Purwokerto Utara, Kabupaten Banyumas, \\ Jawa Tengah 53122
}

\begin{abstract}
The Children's Forum is a forum for children's participation in development that bridges children's aspirations to the government. Child-friendly Cities/Districts aim to ensure the fulfillment of children's rights in a city/district. Both were formed by the Ministry of Women's Empowerment and Child Protection, so their existence is interrelated with each other. In Banyumas Regency both have been formed, so that with the presence of the Banyumas Children's Forum, participation can be analyzed as an effort to create a Child-friendly City in Banyumas Regency. This study aims to find out how the participation of the Banyumas Children's Forum in realizing Child-friendly City in Banyumas Regency is viewed from the perspective of multi-stakeholder partnerships using descriptive qualitative research methods. The selection of informants used was purposive sampling technique. Collecting data using interview, documentation and observation methods and data analysis methods using interactive analysis methods. The results showed that the Banyumas Children's Forum was formed by a Decree of the Banyumas Regent, fostered by the Banyumas Regent, and facilitated by the facilitators. However, the relationship between the facilitator and the Banyumas Children's Forum has not been closely intertwined because the task of the facilitator is conditional if the Children's Forum needs assistance. For the Child-friendly City program, it is the responsibility of all stakeholders, including the Banyumas Children's Forum which is included in the Banyumas Child-friendly City Task Force. The Banyumas Children's Forum is included in one of the institutional cluster indicators, which are responsible for realizing Child-friendly City. Therefore, to help realize a Child-friendly City, a Children's Forum has now been formed in 27 sub-districts throughout Banyumas, and it is being targeted to establish a Children's Forum in all villages. The activities of the Banyumas Children's Forum are monitored and evaluated directly by the Banyumas Regent as the supervisor and the Head of the Section for the Fulfillment of Children's Rights of the DPPKBP3A.
\end{abstract}

Keywords: Banyumas Children's Forum, Child-friendly City, Child Participation, Multi Stakeholder Partnerships.

\section{Pendahuluan}

Selain sebagai harapan bagi keluarga, anak menjadi aset yang penting untuk masa depan suatu negara sehingga kehadirannya harus benar-benar dijaga. Anak yang berkualitas akan berperan sebagai salah satu pondasi untuk menjadikan negara yang kuat dan maju.

Menurut Undang-Undang Nomor 35 Tahun 2014 tentang Perlindungan Anak pada pasal 1 ayat 
1 pengertian anak adalah seseorang yang belum berusia 18 tahun, termasuk anak yang masih dalam kandungan.

Berdasarkan data data Profil Anak Indonesia 2020 yang dipublikasikan oleh Kementerian Pemberdayaan Perempuan dan Perlindungan Anak, jumlah Anak di Indonesia tahun 2019 mencapai 84,4 juta, jumlah tersebut menjadikan Indonesia berada diposisi keempat di dunia sebagai negara yang memilik jumlah anak terbanyak. Tingginya angka tersebut memunculkan berbagai persoalan, masih banyak anak-anak di Indonesia yang belum merasakan hak yang seharusnya diperoleh. Maka dari itu, gambaran anak Indonesia tersebut menjadi sasaran program perlindungan hak anak yang diupayakan oleh Pemerintah Indonesia, terutama oleh Pemerintah Daerah sebagai pemerintah yang dekat secara langsung dengan kehidupan anak, sehingga dituntut untuk lebih pro aktif dan kritis terhadap pemenuhan hak-hak anak (Roza \& S, 2018).

Pemerintah

Republik

Indonesia pada tahun 1990, kemudian meratifikasi Konvensi Hak Anak PBB melalui Keputusan Presiden Nomor 36 tahun 1990. Untuk menguatkan ratifikasi, disahkan pula Undang-Undang Perlindungan Anak Nomor 23 tahun 2002. Sejak saat itu, pemerintah kemudian mulai merumuskan strategi-strategi untuk mengimplementasikan kebijakan ataupun program dengan tujuan untuk mewujudkan pemenuhan hakhak anak. Salah satunya melalui Peraturan Menteri Pemberdayaan Perempuan dan Perlindungan Anak Republik Indonesia Nomor 11 Tahun 2011 Tentang Kebijakan
Pengembangan Kota Layak Anak. Adapun lima tahapan penilaian bagi suatu daerah untuk menuju Kabupaten/Kota Layak Anak (KLA), dimulai dari pratama, madya, nidya, utama, dan Kota Layak Anak. Dari setiap tahapan tersebut ada beberapa indikator yang harus terpenuhi. Sebagai upaya lain untuk menjamin keberlangsungan hak-hak anak, dibentuk juga organisasi Forum Anak yang diatur melalui Peraturan Menteri Pemberdayaan Perempuan dan Perlindungan Anak Nomor 18 Tahun 2019 tentang Penyelenggaraan Forum Anak. Organisasi Forum Anak merupakan organisasi berjenjang dari mulai desa/kelurahan hingga ke tingkat regional dan internasional.

Di Kabupaten Banyumas program Kabupaten Layak Anak telah diluncurkan dan baru memasuki tahapan awal yaitu pratama. Telah terbentuk juga Forum Anak Banyumas sebagai wadah partisipasi anak yang menjadi mitra pemerintah yang konsern dalam isu pembangunan, khususnya untuk mewujudkan Kota Layak Anak. Dalam hal ini perspektif multi stakeholder partnerships atau kemitraan multipihak dapat digunakan untuk mengkaji hubungan keduanya karena dalam pelaksanaan pembangunan tidak hanya melibatkan sekedar pemerintah, tetapi aktor diluar pemerintah yakni anak-anak yang tergabung kedalam Forum Anak Banyumas.

Keterlibatan Forum Anak dengan pemerintah, interaksinya ditunjukkan seperti pada setiap musyawarah perencanaan pembangunan atau agenda perencanaan program kerja pemerintah tahunan, dimana Forum Anak Banyumas selalu diberikan kesempatan untuk menyampaikan 
poin-poin aspirasi anak dalam kerangka "Suara Anak Banyumas" yang kemudian disampaikan dan akan ditanggapi oleh eksekutif dan legislatif. Setiyoningsih et al., (2017) dalam penelitiannya menyatakan bahwa partisipasi adalah salah satu hak dasar yang harus dimiliki oleh setiap anak, maka dari itu dukungan oleh berbagai pihak termasuk dari orang tua juga sangat penting untuk memberikan kebebasan pada anak agar dapat berpartisipasi dalam Forum Anak, dengan didapatkannya dukungan dari berbagai pihak, anakanak akan lebih mudah mengekspresikan diri mereka dalam berbagai kegiatan di Forum Anak.

Berdasarkan uraian diatas, dapat diketahui bahwa Kabupaten Banyumas telah ada program Kabupaten Layak Anak yang masih berada di tahap pratama, dan juga telah mendirikan Forum Anak Banyumas. Maka dari itu menarik untuk dikaji mengenai keterlibatan dari Forum Anak Banyumas dalam mewujudkan Kabupaten Layak Anak di Kabupaten Banyumas menggunakan perspektif multi stakeholder partnerships yang akan menekankan kemitraan antara Forum Anak Banyumas dengan Pemerintah. Kabupaten Banyumas

\section{Metode Penelitian}

Metode penelitian yang digunakan dalam penelitian ini yaitu metode kualitatif deskriptif. Penelitian ini dilaksanakan di kantor Dinas Pengendalian Penduduk Keluarga Berencana Pemberdayaan Perempuan dan Perlindungan Anak (DPPKBP3A) Kabupaten Banyumas. Pemilihan lokasi didasarkan atas lokasi sekretariatnya Forum Anak Banyumas, dan Kabupaten Banyumas yang telah membentuk program
Kabupaten Layak Anak. Pemilihan informan menggunakan teknik purposive sampling. Pengumpulan data menggunakan wawancara mendalam, observasi, dan studi dokumentasi. Metode Analisis data yang digunakan yaitu metode analisis interaktif.

\section{Hasil dan Pembahasan}

$\begin{array}{lcr}\quad \text { Pada } & \text { penelitian } & \text { ini } \\ \text { menggunakan } & \text { model } & \text { multi } \\ \text { stakeholder } & \text { partnerships } & \text { yang }\end{array}$ dikembangkan oleh Brouwer dkk (2015). Di dalamnya memperkenalkan model proses kemitraan yang digunakan untuk merancang dan mengembangkan multi stakeholder partnerships. Model menguraikan fase utama dari multi stakeholder partnerships dan pertimbangan utama pemangku kepentingan yang efektif untuk berkolaborasi. Fase-fase tersebut terdiri dari 4 tahapan yakni; inisiasi, perencanaan adaptif, aksi kolaboratif, monitoring yang reflektif. Pada Forum Anak Banyumas membentuk proses kemitraan dengan stakeholders sebagai berikut:

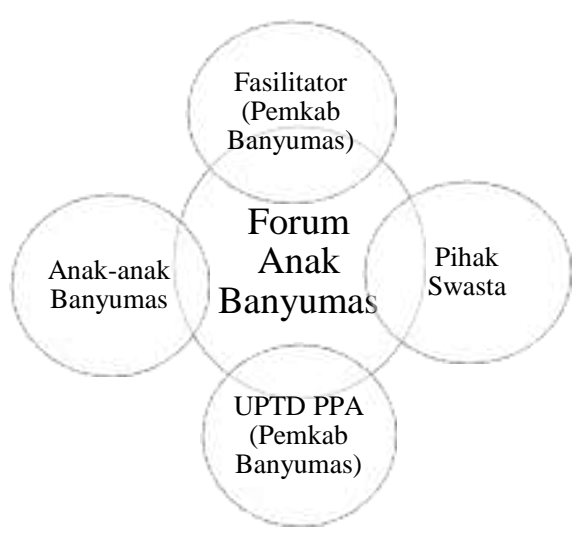

Gambar : Multi stakeholder partnerships pada Forum Anak Banyumas. 
Brouwer dkk (2015) menjelaskan bahwa multi stakeholder partnerships dapat dimulai dengan berbagai cara termasuk dari hasil kebijakan yang dibuat oleh pemerintah, hal tersebut sejalan dengan tahapan inisiasi ini bahwa Forum Anak Banyumas disahkan melalui Surat Keputusan Bupati Banyumas, dibina oleh Bupati dan dibimbing oleh Kepala Seksi Pemenuhan Hak Anak DPPKBP3A Kabupaten Banyumas. Tujuan dibentuknya yakni sebagai media penyalur aspirasi anak-anak Banyumas, sebagai pelopor dan pelapor dan juga perlindungan khusus bagi anak-anak yang berkebutuhan khusus. Dengan dibentuknya Forum Anak ini mengubah persepktif perencana pembangunan bahwa suara anak menjadi penting untuk dipertimbangkan. Forum Anak merupakan salah satu indikator dari cluster kelembagaan dalam mewujudkan Kabupaten Layak Anak. Untuk Kabupaten Layak Anak di Banyumas di launching oleh Bupati Banyumas pada tahun 2013. Berdasarkan pendapat Brouwer dkk (2015), dalam multi stakeholder partnerships dibutuhkan tim yang memprakarsai, mengatur, dan/atau mendukung multi stakeholder partnerships. Untuk itu dibentuklah Gugus Tugas yang bertujuan mempercepat dan membantu proses Kabupaten Banyumas ke tingkatan Kabupaten Layak Anak dan Forum Anak Banyumas dijadikan sebagai anggota.

Forum Anak Banyumas diperbolehkan mendapat bantuan lain diluar pemerintah untuk membantu menunjang keberlangsungan program atau kegiatan. Untuk program Kabupaten
Layak Anak peran serta pihak lain nampaknya masih kurang bahkan belum ada. Hal tersebut dikarenakan Pemerintah Kabupaten Banyumas kurang secara proaktif menggerakan sumber daya yang ada di Kabupaten Banyumas. Pada Forum Anak Banyumas fasilitator sudah tercantum pada SK Bupati, yakni Organisasi Perangkat Daerah yang memiliki keterkaitan dengan anak bertugas untuk memfasilitasi apabila Forum Anak membutuhkan bantuan. Adapun PPT PKBGA yang sekarang berganti menjadi UPTD PPA membantu mewujudkan Kabupaten Layak Anak dalam indikator kelembagaan, bekerja secara praktis dalam perlindungan anak dengan berkontribusi untuk menjamin bahwa anak-anak yang mendapatkan kekerasan dan berdampingan dengan hukum mendapat bantuan hukum.

Pada fase perencanaan adaptif, pemahaman stakeholders yang menjadi fasilitator nampaknya masih kurang, dalam Surat Keputusan Bupati mengenai pembentukan Forum Anak Banyumas tidak dijelaskan mengenai tugas dan fungsi dari adanya fasilitator. Berdasarkan Peraturan Menteri PPPA Nomor 18 Tahun 2019 tentang Penyelenggaraan Forum Anak, fasilitator yaitu orang dewasa yang telah memenuhi syarat umum untuk memfasilitasi Forum Anak, dalam melaksanakan tugasnya berlandaskan pada prinsip umum Konvensi Hak Anak. Untuk dukungan lainnya, para orang tua sudah memiliki pemahaman mengenai Forum Anak Banyumas dan mendukung upaya untuk mewujudkan Kabupaten Layak Anak Banyumas. Selanjutnya, dalam perumusan tujuan, anak-anak diluar pengurus Forum Anak Banyumas tidak dilibatkan secara langsung, 
namun dijadikan objek dari kegiatankegiatan yang dibuat oleh Forum Anak Banyumas, sehingga semua rencana dikoordinasikan secara internal oleh kepengurusan Forum Anak Banyumas dan diwakilkan oleh 27 Forum Anak Kecamatan. Salah satu kegiatan yang telah dilaksanakan yaitu Dialog Anak Bersama Bupati Banyumas, dimana anak-anak yang berpartisipasi menjadi perwakilan, menyampaikan aspirasinya kepada Bupati Banyumas. Tujuan kedepan yang direncanakan yaitu agar seluruh anak-anak Banyumas lebih diperhatikan dan seluruh pemangku kepentingan lebih memerhatikan pemenuhan hak-hak anak. Maka dari itu, digunakan strategi untuk mengembangkan Forum Anak Banyumas dengan dibentuknya Forum Anak di tingkat kecamatan dan senantiasa menyesuaikan kebutuhan anak-anak Banyumas yang sifatnya dinamis dan selalu berubah. Dalam menjalankan tugasnya, para fasilitator membantu dengan sifatnya yang kondisional yakni apabila Forum Anak membutuhkan bantuan. Sejauh ini yang banyak membantu Forum Anak Banyumas yakni DPPKBP3A sebagai pengampu terutama Bidang Perlindungan Anak dan Bappedalitbang sebagai perencana pembangunan di Kabupaten Banyumas.

$$
\text { Selanjutnya fase aksi }
$$

kolaboratif, kegiatan dari Forum Anak sejauh ini banyak disesuaikan dengan situasi pandemi Covid-19 yang menantang untuk semakin kreatif, terlebih lagi karena tuntutan kegiatan yang harus dilaksanakan secara daring. Salah satunya yang baru dilaksanakan yakni Peringatan Hari Anak Nasional pads 23 Juli 2021, pada acara tersebut disampaikan sepuluh poin Suara Anak Banyumas yang dirumuskan oleh Forum Anak Banyumas dan perwakilan dari 27 Forum Anak Kecamatan, disampaikan kepada pemerintah dengan harapan dapat ditindak lanjuti. Ditahun depan direncanakan bahwa setiap dinas di Kabupaten Banyumas akan mengalokasikan anggarannya untuk anak dan Forum Anak Banyumas sebagai pelaksanannya. Dalam upaya mewujudkan Kabupaten Layak Anak dimana salah satu dari indikatornya adalah terdapat Forum Anak ditingkat desa/kelurahan bahkan ketingkat RW, Forum Anak Banyumas kini telah mendirikan Forum Anak Kecamatan di 27 Kecamatan seBanyumas dan sedang menargetkan pembentukan Forum Anak di seluruh desa/kelurahan yang ada di Kabupaten Banyumas. Dalam struktur manajemen program, Forum Anak Banyumas membentuk bidang baru yakni Bidang Koordinator Wilayah yang menjembatani komunikasi antara Forum Anak Banyumas dengan Forum Anak Kecamatan, serta terdapat Bidang Publikasi dan Dokumentasi yang mengelola media sosial. Untuk susunan kepengurusan Forum Anak Kecamatan hampir sama dengan Forum Anak Banyumas, perbedaanya terletak pada fasilitator saja. Dalam mengimplementasikan program, Forum Anak banyak memanfaatkan media sosial terutama Instagram agar dapat membagikan informasi dan juga untuk berinteraksi dengan anakanak Banyumas. Pada Forum Anak Banyumas segala hal yang mengharuskan bekerja sama dengan pihak luar, harus dikonsultasikan dulu kepada Kasi Pemenuhan Hak Anak sebagai pembimbing. Untuk Kabupaten Layak Anak, seharusnya pemerintah Kabupaten Banyumas dapat memanfaatkan sumber daya 
yang ada di Banyumas, salah satunya seperti bekerja sama dengan stakeholder yang ada di Banyumas.

Fase terakhir yakni monitoring yang reflektif, pada fase ini terletak dipusat model proses multi stakeholder partnerships dan tertanam pada fase lainnya. Anakanak yang tergabung kedalam Forum Anak Banyumas sudah memiliki pengalaman berorganisasi, tidak sulit bagi mereka untuk menyesuaikan diri dalam menjalankan organisasi karena memiliki pengalaman sebelumnya yang dapat dijadikan pembelajaran ketika bergabung dengan Forum Anak. Dalam menjalankan tugasnya, di Forum Anak juga terdapat prinsipprinsip yang dipegang seperti tidak adanya diskriminasi dan senioritas, sehingga anak-anak akan lebih nyaman dengan budaya organisasi tersebut. Untuk memantau kegiatan Forum Anak Banyumas, anak-anak sering berkoordinasi dengan pengurus sebelumnya untuk meminta pendapat, dan juga karena sekretariatnya berada di kompleks DPPKBP3A, kegiatannya pun dipantau langsung oleh Kepala Seksi Pemenuhan Hak Anak DPPKBP3A. Kemajuan yang telah Forum Anak Banyumas capai perlu ditinjau dan dievaluasi. Untuk itu, terdapat agenda rutin bersama Bupati Banyumas sebagai pembina maupun dengan DPPKBP3A sebagai pengampu. Bagi Forum Anak Kecamatan terjadwal pula agenda evaluasi yang dilaksanakan bersama Koordinator Wilayah. Forum Anak Banyumas senantiasa selalu didampingi oleh Kasi Pemenuhan Hak Anak maka dari itu apabila terdapat kekurangan seperti kendala akan cepat teratasi.

\section{Kesimpulan}

Forum
Anak Banyumas disahkan melalui Surat Keputusan Bupati, dibimbing oleh Kepala Seksi Pemenuhan Hak Anak DPPKBP3A dan dibina oleh Bupati Banyumas. Tujuannya yakni sebagai media penyalur aspirasi anak-anak, sebagai pelopor dan pelapor dan juga perlindungan khusus. Forum Anak Banyumas termasuk dalam salah satu indikator cluster kelembagaan dalam mewujudkan Kabupaten Layak Anak. Suara anak menjadi penting bagi perencanaan pembangunan. Forum Anak diperbolehkan mendapat bantuan lain untuk menunjang keberlangsungan program atau kegiatan. Untuk program Kabupaten Layak Anak telah dibentuk Gugus Tugas dan Forum Anak Banyumas dijadikan anggotanya, meskipun pada eksekusi tugasnya belum dapat bersinergi dengan pihak lain diluar pemerintah, dikarenakan kurang secara proaktif menggerakan sumber daya yang ada.

Anak-anak diluar pengurus Forum Anak Banyumas dijadikan objek dari kegiatan-kegiatan yang dibuat oleh Forum Anak Banyumas dan Forum Anak Kecamatan. Strategi untuk mengembangkan Forum Anak Banyumas senantiasa menyesuaikan kebutuhan anak-anak Banyumas yang sifatnya dinamis. Fasilitator dalam melaksanakan tugasnya berlandaskan pada prinsip umum Konvensi Hak Anak (KHA), kontribusinya Forum Anak sifatnya kondisional apabila Forum Anak membutuhkan bantuan. Sejauh ini yang banyak membantu Forum Anak Banyumas yakni DPPKBP3A sebagai pengampu terutama Bidang Perlindungan Anak dan Bappedalitbang sebagai perencana pembangunan di Kabupaten Banyumas.

Sejauh ini kegiatan Forum 
Anak tidak sedikit dilaksanakan secara daring. Salah satunya Peringatan Hari Anak Nasional dimana disampaikan sepuluh poin Suara Anak Banyumas kepada pemerintah dengan harapan dapat ditindak lanjuti. Rencananya tahun depan, setiap dinas di Kabupaten Banyumas akan mengalokasikan anggarannya untuk anak dan Forum Anak Banyumas sebagai pelaksanannya. Kini telah didirikan 27 Forum Anak Kecamatan seBanyumas dan sedang ditargetkan pembentukan Forum Anak di seluruh desa/kelurahan. Dengan dibentuknya Forum Anak Kecamatan, maka dibentuk juga bidang baru yakni Bidang Koordinator Wilayah yang menjembatani komunikasi antara Forum Anak Banyumas dengan Forum Anak Kecamatan, serta terdapat Bidang Publikasi dan Dokumentasi dalam pemanfaatan media sosial. Segala hal yang mengharuskan bekerja sama dengan pihak luar, harus dikonsultasikan dulu kepada Kasi Pemenuhan Hak Anak sebagai pembimbing.

Budaya organisasi yang terbentuk pada Forum Anak Banyumas yakni tidak adanya diskriminasi dan senioritas. Untuk memantau kegiatan Forum Anak Banyumas, karena sekretariatnya berada di kompleks DPPKBP3A maka dipantau langsung oleh Kepala Seksi Pemenuhan Hak Anak DPPKBP3A. Selain itu, terdapat agenda evaluasi rutin bersama Bupati Banyumas maupun dengan DPPKBP3A sebagai pengampu. Bagi Forum Anak Kecamatan terjadwal pula agenda evaluasi yang dilaksanakan bersama Koordinator Wilayah.

\section{Referensi}

\section{Buku:}

Brouwer, J. H., Woodhill, A. J., Hemmati, M., Verhoosel, K. S., \& van Vugt, S. M. 2015. The MSP guide: How to design and facilitate multi-stakeholder partnerships. Centre for Development Innovation Wageningen UR.

Buckup, S. 2012. Building successful partnerships. A production theory of global multi-stakeholder collaboration. Wiesbaden: SpringerGabler.

Bungin, Burhan. 2012. Analisis Data Penelitian Kualitatif. Jakarta: Raja Grafindo Persada.

Moleong, Lexy. J. 2015. Metodologi Penelitian Kualitatif. Bandung: PT Remaja Rosdakarya.

Rosmaladewi, 0. 2018. Manajemen Kemitraan Multistakeholder Dalam Pemberdayaan Masyarakat. Yogyakarta: Deepublish.

Saldana., Miles \& Huberman. 2014. Qualitative Data Analysis. America: SAGE Publications.

Stern, A., Kingston, D., \& Ke, J. 2015. More than the sum of its parts: Making multi-stakeholder initiatives work. Washington DC: Global Development Incubator (GDI).

Sugiyono, S. 2020. Metode Penelitian Kualitatif untuk Penelitian yang Bersifat: Eksploratif, Enterpretif, Interaktif dan Konstruktif. Bandung: CV. Alfabeta.

\section{Jurnal/Artikel Ilmiah:}

Almira, R., \& Paselle, E. 2020. Implementasi Program Forum Anak dalam Penanggulangan Kenakalan Anak di Kecamatan Sungai Pinang Kota Samarinda. 
Journal of Policy \& Bureaucracy Management, 1(1), 22-33.

Dewi, N. L. Y. 2019. Dinamika Collaborative Governance Dalam Studi Kebijakan Publik. Jurnal Ilmiah Dinamika Sosial, 3(2), 200-210.

Dodds, F., Strandenaes, J.-G., Hemmati, M., Chopitea, C. D., Lakemeier, B., Salz, S., Borkenhagen, J., Schmitz, L., \& Strandenaes, J.-G. 2019. Multi stakeholder partnerships. Stakeholder Democracy, 164-193. Fithriyyah, M. U. 2017. Studi Implementasi Kebijakan Kota Layak Anak (KLA) https://doi.org/10.4324/978135 1174428-8. di Kota Pekanbaru. Transparansi. Jurnal Ilmiah Ilmu Administrasi, 9(2), 154-171. DOI: https://doi.org/10.31334/trans. v9i2.21.g20.

Hamudy, M. I. A. 2015. Upaya Mewujudkan Kota Layak Anak di Surakarta dan Makassar. Jurnal Bina Praja: Journal of Home Affairs Governance, 7(2), 149160. DOI: https://doi.org/10.21787/jbp.07 .2015.149-160.

Himawati, I. P., Nopianti, H., Hartati, S., \& Hanum, S. H. 2016. Analisis Pemenuhan Hak Dasar Anak Pada Program "Kota Layak Anak" Di Kecamatan Gading Cempaka, Bengkulu. Jurnal Ilmu Sosial Mamangan, 5(1), 37-49. DOI:https://doi.org/10.22202/m amangan.1928.

Horgan, D., Forde, C., Martin, S., \& Parkes, A. 2017. Children's participation: Moving from the performative to the social. Children's Geographies, 15(3), 274-288.

DOI: http://dx.doi.org/10.1080/1473 3285.2016.1219022.
Ikhsan, N., Nur, S. A., \& A'yun, L. Q. 2020. Kemitraan Pemerintah Daerah dan Lembaga Swadaya Masyarakat Dalam Pengelolaan Rumah Hati Rumah Bakat di Kota Makassar. Prosiding Simposium Nasional "Tantangan Penyelenggaraan Pemerintahan di Era Revolusi Indusri 4. 0. 954977.

Kurniawati, D. O., \& Marom, A. 2020. Implementasi Kebijakan Kabupaten Layak Anak dengan Pendekatan Desa Ramah Anak Di Desa Gunem Kecamatan Gunem Kabupaten Rembang. Journal of Public Policy and Management Review, 9(2), 35-53. DOI: https://doi.org/10.14710/jppmr. v9i2.26972.

Lawado, I. S., \& Na'imah, N. 2019. Strategi Pemberdayaan Anak Melalui Wadah Partisipasi Anak Sebagai Upaya Pemajuan Hak Asasi Manusia. Egalita, 13(1), 51-63.

DOI: https://doi.org/10.18860/egalit a.v13i1.8078.

Lee, C. 2019. Studi Tentang Pelaksanaan Program Kota Layak Anak Di Kecamatan Sungai Kunjang Kota Samarinda.

Liwananda, M. T. T., \& Astrika, L. 2020. Studi Evaluasi Kebijakan Kota Layak Anak (KLA) dalam Pemenuhan Klaster Hak Sipil dan Kebebasan di Kota Semarang. Journal of Politic and Government Studies. 9(02), 71-80.

Manghayu, A., \& Mulawati, N. A. H. 2019. Manajemen Pemangku Kepentingan Dalam Ranah Pengambilan Keputusan Pemerintah Daerah. Institut Pemerintahan Dalam Negeri.

Momen, M. N. 2020. Multistakeholder partnerships in public policy. Partnerships for 
the goals. Encyclopedia of the UN sustainable development goals, 1-9.

Nurhayati, S., Oktaviana, D., \& Anandari, D. 2017. Implementasi Program Desa Layak Anak Di Kabupaten Banyumas. Prosiding, $7(1)$.

Pert, H., Diaz, C., \& Thomas, N. 2017. Children's participation in LAC reviews: a study in one English local authority. Child \& Family Social Work, 22, 1-10. DOI: https://doi.org:10.1111/cfs.1219 4.

Rizki, D. A., Sulastri, S., \& Irfan, M. 2015. Pemenuhan Hak Partisipasi Anak Melalui Forum Anak Dalam Implementasi Kebijakan Kota Layak Anak Di Kota Bandung. Share: Social Work Journal, 5(1), 360-362. DOI:

https://doi.org/10.24198/share. v5i1.13085.

Rizki, E. A., Warsah, I., \& Jaya, G. P. 2020. Kontribusi forum anak daerah Kepahiang provinsi Bengkulu (FADEK) dalam perlindungan hak anak. Yinyang: Jurnal Studi Islam Gender Dan Anak, 207-224. DOI: https://doi.org/10.24090/yinya ng.v15i2.3947.

Roza, D., \& S, L. A. 2018. Peran Pemerintah Daerah Untuk Mewujudkan Kota Layak Anak Di Indonesia. Jurnal Hukum Ius Quia Iustum, 25(1), 198-215. DOI: https://doi.org/10.20885/iustu m.vol25.iss1.art10.

Rosmaladewi, 0., \& Irmawatie, L. 2015. Kemitraan Multistakeholder dalam Pengelolaan Hutan Bersama Masyarakat di Kawasan Hutan Darajat Kabupaten Garut. JURNAL PENGABDIAN

KEPADA
MASYARAKAT, 5(1), 28-36. DOI: http://dx.doi.org/10.30999/jpk m.v5i1.49.

Saputri, F. A., \& Erowati, D. 2020. Strategi Pengembangan Kabupaten/Kota Layak Anak di Kabupaten Kebumen Tahun 2019. Journal of Politic and Government Studies, 9(02), 191200.

Setiyoningsih, D. A., \& Yuliani, S. 2017. Partisipasi Forum Anak dalam Implementasi Kebijakan Kelurahan Layak Anak di Kota Surakarta (Studi Tentang Partisipasi Forum Anak Jebres di Kelurahan Jebres). Jurnal Wacana Publik, 1(1), 46-55.

Sloan, P., and Oliver, D. 2013. Building Trust in Multi-stakeholder Partnerships: Critical Emotional Incidents and Practices of Engagement. In Organisational Studies 34 (12), p1835-1868

Sirajuddin, M., \& Kamil, S. U. R. 2017. Youth Participation In Development Acceleration of Kolaka Utara Regency (A Case Studies in Forum Anak Kokekoke). In Third International Conference on Social and Political Sciences (ICSPS 2017). Atlantis Press.

DOI: https://dx.doi.org/10.2991/icsps -17.2018 .82 .

Suherlan, H., Hidayah, N., Mada, W. R., Nurrochman, M., \& Wibowo, B. (2020). Kemitraan Strategis Antar Stakeholder Dalam Pengembangan Desa Wisata Gubugklakah Kab. Malang, Jawa Timur. Jurnal Pariwisata Terapan, 4(1), 59-72. DOI: https://doi.org/10.22146/jpt.53 303.

Sulistiowati, R., Meiliyana, M., Ma'arif, S., \& Meilinda, S. D. 2020. Stakeholder Partnership in the 
Management of Marine Tourism in South Lampung Regency, Lampung. Indonesian Journal of Tourism and Leisure, 1(2), 82-91. DOI:

https://doi.org/10.36256/ijtl.v1i 2.105 .

Thoomaszen, F. W. 2017. Peran keluarga dalam pemenuhan hak partisipasi anak pada Forum Anak Kota Kupang (FAKK). Persona: Jurnal Psikologi Indonesia, 6(2), 82-97. DOI: https://doi.org/10.30996/perso na.v6i2.1298.

Wangke, H. 2017. The anagement of Kutai National Park through the multi stakeholder partnership. In 1st International Conference on Administrative Science, Policy and Governance Studies (ICAS-PGS 2017) and the 2nd International Conference on Business Administration and Policy (ICBAP 2017) (pp. 343-352). Atlantis Press. DOI: https://dx.doi.org/10.2991/icas pgs-icbap-17.2017.43.

Wulandari, A., \& Taufiq, A. 2019. Partisipasi Masyarakat dalam Mewujudkan Kota Layak Anak di Kota Surakarta. Journal of Politic and Government Studies, 8(03), 51-60.

\section{Peraturan/Kebijakan:}

Keputusan Presiden Nomor 36 tahun 1990 tentang Pengesahan Konvensi Hak-Hak Anak

Undang-Undang Nomor 35 Tahun 2014 tentang Perlindungan Anak (UUPA)

Undang-Undang Perlindungan Anak Nomor 23 tahun 2002

Peraturan Menteri Pemberdayaan Perempuan dan Perlindungan Anak Republik Indonesia Nomor 3 Tahun 2011 Tentang Kebijakan
Partisipasi Anak Dalam

Pembangunan Pasal 1 Ayat 2

Peraturan Menteri Pemberdayaan Perempuan dan Perlindungan Anak Nomor 18 Tahun 2019 tentang Penyelenggaraan Forum Anak

Peraturan Menteri Pemberdayaan Perempuan dan Perlindungan Anak Republik Indonesia Nomor 11 Tahun 2011 tentang Kebijakan Pengembangan Kota Layak Anak

Peraturan Menteri Pemberdayaan Perempuan dan Perlindungan Anak Republik Indonesia Nomor 12 Tahun 2011 tentang Indikator Kabupaten/Kota Layak Anak

Peraturan Presiden Nomor 59 Tahun 2017 tentang Pelaksanaan Pencapaian Tujuan Pembangunan Berkelanjutan

Lainnya:

Affandi, Thohir. 2017. Bonus Demografi 2030-2040:

Strategi Indonesia Terkait

Ketenagakerjaan dan

Pendidikan.

https://www.bappenas.go.id/file s/9215/0397/6050/Siaran_Pers _Peer_Learning_and_Knowledge_ Sharing_Workshop.pdf. Diakses pada 11 Desember 2020.

Anonim. 2019, Kasus Kekerasan Terhadap Anak Tertinggi. https://suarabanyumas.com/20

19-kasus-kekerasan-terhadapanak-tertinggi/. Diakses pada 18 Desember 2020.

Child Friendly Cities. https://childfriendlycities.org/. Diakses pada 02 Februari 2020. Effendi, Hermiana E. 2019. Banyumas Kota Layak Anak Tahap Pratama. https://www.cendananews.com/ 2019/01/banyumas-kota-layak- 
anak-tahap-pratama.html.

Diakses pada 21 Desember 2020.

Forum

Anak

Nasional.

www.forumanak.id/data. Diakses pada 28 Januari 2021.

Humas Bappenas. 2019. Peluncuran Buku Panduan Kemitraan Multi Pihak (KMP) untuk Mendukung Pelaksanaan Tujuan Pembangunan Berkelanjutan (TPB/SDGs).

https://www.bappenas.go.id/id/ berita-dan-siaranpers/peluncuran-buku-panduankemitraan-multi-pihak-kmpuntuk-mendukung-pelaksanaantujuan-pembangunanberkelanjutan-tpbsdgs/. Diakses pada 16 Maret 2021.

Kemeterian Pemberdayaan Perempuan dan Perlindungan Anak. Bahan Advokasi Kebijakan KLA.

https://www.kemenpppa.go.id/li b/uploads/slider/09e6c-kla.pdf. Diakses pada 15 Desember 2020.

Mutiara, Puput. 2016. Anak Sehat Aset Masa Depan. https://mediaindonesia.com/hu maniora/59018/anak-sehataset-masa-depan. Diakses pada 12 Desember 2020.

Rohman, 2020. Momentum Hari Anak Nasional 2020, Forum Anak Banyumas Sampaikan 10 Butir 'Suara Anak Banyumas'. https://lensabanyumas.pikiranrakyat.com/banyumasan/pr24634250/momentum-harianak-nasional-2020-forum-anakbanyumas-sampaikan-10-butirsuara-anak-banyumas. Diakses pada 12 Desember 2020.

Suprianto, 2020. Bupati: Forum Anak, Mendukung Kabupaten Layak Anak https://rri.co.id/purwokerto/ber ita/banyumas/769095/bupati- forum-anak-mendukungkabupaten-layak-anak Diakses pada 20 Desember 2020.

UNICEF Indonesia. https://www.unicef.org/indones ia/id/konvensi-hak-anak-versianak-anak. Diakses pada 12 Desember 2020. 